DOI: $10.17805 /$ zpu.2019.1.9

\title{
Конструирование социальной реальности в техносоциальном пространстве: новые вопросы и идеи
}

\author{
А. Н. Пинчук \\ ИНСТИТУТ СОЦИАЛЬНО-ПОЛИТИЧЕСКИХ ИССЛЕДОВАНИЙ РАН
}

В статье рассматривается развитие концептуальных идей о конструировании новой социальной реальности в контексте перехода от социального к техносоциальному пространству. Представлены глобальные инновационные тренды, способные в долгосрочной перспективе значительно изменить облик информационно-технологической инфраструктуры, что сопряжено с серьезными социальными эффектами. Анализируются ключевые работы последователей феноменологического направления, акцентирующих ментальную сторону конструирования социальной реальности. Изучены концепции материалистической феноменологии, в рамках которой переосмысливается роль медиатехнологий в формировании социальной реальности.

С опорой на концепт медиатизации показывается трансформация коммуникативных фигураций, преобразование социального пространства и времени, подчеркивается возрастающая роль датификации. Отмечается интеграция феноменологической мысли в разработки новой междисциплинарной отрасли научного знания - человеко-компьютерное взаимодействие.

Ключевые слова: социальная реальность; конструирование социальной реальности; инновационные технологии; техносоциальное пространство; феноменологический подход; материалистическая феноменология

\section{ВВЕАЕНИЕ}

$\mathrm{M}$ еняющийся облик современного мира требует своевременного научного осмысления, постановки новых исследовательских вопросов. Однако в опыте исследовательской практики особое место занимают такие вопросы, которые по своей сути являются стержневыми для предметного поля науки. Здесь требуется не только верно ориентироваться в концептуальном поле предметной области, но и нередко переосмыслить существующие идеи, расширяя их познавательный потенциал применительно к современным условиям.

Так, в поисках наиболее исчерпывающей объяснительной модели часто совершается ревизия различных теоретических построений и их последовательное рассмотрение в новом контексте. Аанные особенности прослеживаются в траектории развития вопроса о конструировании социальной реальности, который в информационном обществе приобретает особое звучание, требуя перефокусировки социологической оптики. Приобретая глобальные масштабы, технологическое усовершенствование различных сфер деятельности человека не только преобразовало формы социальной жизни, но и привело к созданию новых рамок ее освоения. В этих условиях будущие картины мира начинают вырисовываться на фоне «протоинформационной», «протовиртуальной» эпохи, а современное социальное пространство приобретает качественно новые характеристики, переходя к техносоциальному (Эпштейн, 2004).

Сложность в том, что тенденции развития инновационных технологий набирают все больше оборотов, экспоненциально увеличивая свою роль в жизни общества и определяя вектор будущих изменений. В технологическом мейнстриме по инерции трансформируются социальные практики, процессы социальной коммуникации, ре- 
формируются общественные институты, преобразуется отношение человека к окружающему миру. В то же время видоизменяется и само взаимодействие индивида и техники, усложняется связь между усовершенствованными технологиями и функционированием общества.

Сегодня можно отметить следующие приоритетные разработки, способные обновить облик информационно-технологической инфраструктуры (вместе с тем имеющие определенные социальные эффекты) в долгосрочной перспективе:

- развитие искусственного интеллекта, машинного обучения и робототехники, которые значительно расширят потенциальные возможности индивида. Ученые отмечают модернизацию различных отраслей деятельности человека посредством использования автономных систем на основе искусственного интеллекта и коммуникаций, а также промышленных и сервисных роботов, в том числе для домашних приложений (Keisner, Raffo, Wunsch-Vincent, 2016);

- системная трансформация медиа, развитие дисплейных систем, рост потребительских свойств телевизионного и видеоконтента, усложнение и усовершенствование цифрового контента (ЦК), в том числе создаваемого потребителями (user - generated content - UGC) (Калинин, 2010: Электронный ресурс);

- внедрение технологии grid-сетей, реализующих новые принципы конфигурации компьютерных систем. При переходе от модели владения материальными ИКТ-активами (asset ownership) к моделям ИКТ-сервисов (service provisioning) прогнозируется создание платформы для «...конвергенции grid-сетей, Web-сервисов и семантических технологий; интенсивного развития сервис-ориентированных архитектур, обеспечивающих интеграцию массовых сервисов, включая те, что относятся к категории “Интернета вещей” (Гиглавый и др., 2013: 17);

- распространение и внедрение интернет-вещей по аналогии с развитием сложного организма, объединяющего множество раздичных устройств, сенсоров и других объектов, в единую онлайн-сеть, способную отслеживать и фиксировать различные операции, в том числе «...информировать о ходе их выполнения, контролировать их и принимать необходимые меры в режиме реального времени без участия людей, генерируя при этом беспрецедентный объем данных» (Kergroach, 2017: 6);

- возможность получать и изучать большие данные (big data), которые отличаются всеохватывающим и исчерпывающим объемом (они включают терабайты и петабайты данных), непрерывным производством, детализацией, гибкостью и расширяемостью. Большие базы данных планируется анализировать с помощью новых аналитических методик, основанных на исследованиях в сфере искусственного интеллекта и экспертных систем (Китчин, 2017);

- разработка технологий физического и когнитивного совершенствования человека, посредством медицинского, фармацевтического вмешательства, внедрения кремниевых чипов и имплантируемых устройств, а также использования «умных» технологий, ориентированных на «внешнее» применение (Саритас, 2013).

Таким образом, на фоне экстенсивного роста инновационных разработок требуется переосмыслить интеграцию информационных технологий в освоение социального мира. В настоящей статье попытаемся очертить возможные рамки социологической рефлексии по данной тематике и показать новые аспекты теоретической интерпретации конструирования социальной реальности в контексте техносоциального пространства. 
КОНСТРУИРОВАНИЕ СОЦИААЬНОЙ РЕААЬНОСТИ:

\section{ТЕОРЕТИЧЕСКИЕ РАМКИ АНААИЗА}

Приступая к изучению темы о конструировании социальной реальности, следует отметить одну из особенностей социально-гуманитарного знания, которая во многом опосредует сложность теоретического анализа, - наличие различных альтернативных, дополняющих друг друга, а иногда конфликтующих теоретических подходов к исследованию одной и той же тематики.

Ф. Коркюф подчеркивает общую направленность научных разработок в сфере изучения конструирования социальной реальности, которая заключается в стремлении преодолеть классические дихотомии: материальное - идеальное, объективное субъективное, коллективное - индивидуальное или макро - микро (Коркюф, 2002: 9). По мнению Коркюфа, конструктивистские теории объединяет единое поле вопросов и проблем, однако «если каждая из этих позиций пытается преодолеть противоположность между макро- и микросоциологиями, между познанием объединяющих социальных структур и анализом действий и взаимодействий “лицом-к-лицу” самих акторов, то происходит это по-разному в зависимости от того, исходят ли эти позиции из структур или из взаимодействий» (там же: 29).

В соответствии с этим можно обозначить обособляющиеся ветви исследовательской логики, одна из которых восходит к изучению макроструктур, соединяя их с субъективными и интеракционистскими аспектами, другая исходит в своих положениях из исследования индивидов и их взаимодействий, переходя на уровень более широких общностей. Согласно Коркюфу, эти позиции отражают, соответственно, структуралистский и феноменологический конструктивизм (там же). Безусловно, теоретико-методологические перспективы не ограничиваются выделенными подходами, разнообразие которых заслуживает обсуждения в отдельной статье. В представленном срезе научной мысли важно проследить определенную линию анализа, отмечающую референтные точки в теоретическом поле.

Исходя из этого, обратим внимание на феноменологический подход, который послужил развитию посыла к изучению формирования социальной реальности в преломлении воспринимающего и познающего сознания. В техносоциальном мире данный посыл становится особенно актуальным, что связано с изменением способа взаимодействия познающего субъекта с окружающей действительностью. Это относится к разным аспектам жизни социума: социальным коммуникациям, которые переходят в онлайнпространство, где люди могут создавать не соответствующие реальным характеристикам личные профили; к развитию виртуальной реальности, открывающей доступ к искусственно смоделированным мирам; к повышающейся угрозе манипулирования массовым сознанием с применением информационных технологий (Карепова, Пинчук, Некрасов, 2018). Заслуживает внимания и то, что в феноменологическом направлении особое место занимает знание. В современном обществе транслирование, аккумулирование и непрерывное воспроизводство знания преимущественно происходит с использованием информационных технологий (Пинчук, 2016, 2017), которые распределяют знания в электронно-цифровом формате и вытесняют передачу знаний в рамках непосредственного социального взаимодействия. Более того, в связи с развитием инновационных технологий назревает вопрос о том, какую систему знаний усвоит индивид, если с познавательными целями будет обращаться к искусственному интеллекту.

Таким образом, в контексте акцентации ментальной стороны конструирования социальной реальности значительно раскрывается эвристический потенциал феномено- 
логического подхода. Б. Верлен утверждает: «Аля сторонников феноменологической перспективы объективный смысл физической и социальной реальности не является заданным как таковой. Скорее, он представляется как результат осмысленного его выстраивания взаимодействующими субъектами» (Верлен, 2003: 30).

\section{ФЕНОМЕНОАОГИЧЕСКИЙ ПОАХОА}

Один из основоположников феноменологии Э. Гуссерль обратил внимание на различие между физическим «явлением выражения», актом придания смысла, и актом, осуществляющим смысл. Указывая на то, что выражения, наделенные смыслом, включают физическую сторону, ученый также выделяет акт, который придает значение, «созерцательную полноту», конституирует отношение к предмету. Несмотря на то что выражение становится осмысленным и что-то под собой подразумевает (meint), оно в то же время может быть «пустой интенцией значения» (Гуссерль, 2001: 47). Гуссерль вводит данное понятие, чтобы показать отличие «интенции значения», что характеризует звучащее слово, наделенное смыслом, от «интенции осуществления», т. е. акта, который в познании и осуществлении соединен с актом придания значения и актуализирует предметное отношение (там же: 48). Изучая гуссерлевскую концепцию, М. Ришир замечает: «...статическая феноменология показывает, что сознание в целом - это не простая структура: в опыте вещей и мира сознание представляет собой исключительно [плотно] сплетенную ткань интенциональных отношений» (Ришир, 2014: 209). Собственно, артикулирование интенциональности мышления как направленности на определенный предмет извне становится ключевым для феноменологического анализа смысловых структур внутреннего мира. Вместе с тем в феноменологической перспективе любой акт понимания основывается на предшествующем интенциональном опыте, который предполагает наличие ранее накопленного знания о воспринимаемом предмете (Верлен, 2003).

Еще одну важную мысль о формировании общего понимания реальности Гуссерль отмечает в одной из своих ключевых работ «Картезианские медитации»: «...в себе самом, в рамках своей трансцендентально редуцированной чистой жизни сознания, я обладаю опытом мира совместно с Аругими и, в соответствии со смыслом этого опыта, не в качестве своего, так сказать, приватного синтетического формообразования, но в качестве чужого мне мира, в качестве интерсубъективного мира, доступного для каждого в отношении своих объектов» (Гуссерль, 2010: 119).

Идея о значимости интерсубъективности крепко закрепляется в феноменологической традиции и находит развернутое концептуальное выражение в разработках одного из виднейших последователей феноменологии - А. Шюца. Ученый указывает на то, что интерсубъективность сознания репрезентирует тождественность интерпретаций и общность миропонимания, получаемых в результате освоенного опыта в рамках взаимодействия с Аругими: «любая интерпретация мира основана на запасе предыдущих его переживаний, переживаний наших собственных и переданных нам родителями и учителями, которые в форме “наличного знания” функционируют как схема референции» (Щюц, 2003a: 3-4). Тем самым в результате познания мира и конституирования его смысла формируется интерсубъективный запас знания об окружающей реальности. В то же время Шюц указывает на множественность реальностей и выделяет различные миры (мир сновидений, грез и фантазий, мир искусства, религиозного опыта, научного созерцания, игровой мир ребенка и мир безумия), каждый из которых обладает своей конечной областью смысла, «специфическим напряже- 
нием сознания», «еросhе», специфической формой переживания Я и социальности (там же: 17-19).

Интерпретация мира, согласно Щюцу, осуществляется через типизации, которые состоят в «уравнивании черт, релевантных для конкретной непосредственной цели», поэтому сфера повседневного опыта структурирована на основе системы релевантностей, определяющей «что должно быть принято в качестве типически равного (гомогенного) и что - в качестве типически различного (гетерогенного)» (Щюц, 2003b: 271).

В концептуальных рассуждениях Шюца системе релевантностей уделяется особое внимание в рамках анализа социального распределения знания. Согласно пониманию ученого, интеракция с Аругим осуществляется в зоне общих релевантностей, где разделяется взаимное знание. Примечательно то, что Шюц обращает внимание на влияние начинающих в его время активно развиваться технологий, которые провоцируют рост анонимности партнера, заменяя общие релевантности навязанными. «Наше собственное социальное окружение, - пишет ученый, - оказывается доступным каждому и повсюду. Анонимный Аругой, чьи цели неизвестны нам из-за его анонимности, может взять нас вместе с системой наших интересов и релевантностей под свой контроль. У нас все меньше и меньше права определять, что для нас релевантно, а что нет» (там же: 232).

Рассматривая проблему распределения знаний в обществе, Щюц выделяет социально приобретенное знание, получаемое посредством переживания Аругого, и социально одобренное знание, обладающее авторитетным преимуществом из-за поддержки членами мы-группы, оно является основой общественного мнения. Автор подчеркивает значимость социально одобренных знаний, которые придают дополнительный вес мнению эксперта или хорошо информированного гражданина. Однако, как замечает ученый, «опросы, интервью, анкеты пытаются выявить мнение человека с улицы, которого не интересует ничто, выходящее за пределы его привычной системы релевантностей. Его мнение... получает все большее социальное одобрение в ущерб информированному мнению и поэтому навязывается как релевантное более информированным членам общества» (там же: 237). Примечательно, что данное замечание актуально и сегодня.

Особую роль знания в конструировании социальной реальности подчеркивали ученики А. Шюца - П. Бергер и Т. Аукман (Бергер, Аукман, 1995). Следуя традиции феноменологической мысли, авторы сосредоточивают свое внимание на повседневной жизни, «реальность» которой постигается интенциональным сознанием и субъективно интерпретируется. Субъективные смыслы выражаются через объективации, которые посредством языка обозначают и упорядочивают объекты в окружающей человека действительности.

Аукман придает особое значение языку, утверждая, что это главное средство «как социального конструирования реальности, так и главное средство опосредования социально сконструированной реальности» (Аукман, 2007: 17). Смыслы, передающиеся посредством знаковых систем через язык, формируются в опыте. Аукман описывает конструирование смысла, рассматривая тематическое поле и тематическое ядро, составляющие универсальную структуру протекающих в сознании процессов. «Переживания содержат не только актуальные ядра самих фаз переживаний. Каждое переживание содержит наряду с актуальными темами также и аппрезентативные тематические составные части» (там же: 8). В результате восприятия объектов, процессов 
синтеза и аппрезентации формируются типичные образы. Некоторые переживания актуализируются в опыт благодаря тому, что Я уделяет им повышенное внимание, придает особое значение, акцентирует связность с другими типизациями, действиями и т. А., тем самым конституируя смысл опыта (там же: 9).

Бергер и Аукман объясняют, что, объективируя, аккумулируя и выборочно сохраняя индивидуальный и общественный опыт в рамках семантических полей, члены группы формируют запас социального знания, который «дифференцирует реальность по степени знакомства» (Бергер, Аукман, 1995: 75). Причем связь между человеком и социальным миром ученые определяют как диалектическую, основанную на взаимодействии друг с другом. «Экстернализация и объективация - два момента диалектического процесса. Третьим моментом этого процесса является интернализация (посредством которой объективированный социальный мир переводится в сознание в ходе социализации)...» (там же: 103). Знание в этом процессе объективирует мир посредством языка, вместе с тем оно интериоризируется как понимание существующей реальности в результате социализации.

Идея Шюца об интерсубъективном мире становится ключевой в определении Бергером и Аукманом общего миропонимания и разделяемых людьми повседневных знаний: «Реальность повседневной жизни представляется мне как интерсубъективный мир, который я разделяю с другими людьми. Именно благодаря интерсубъективности повседневная жизнь резко отличается от других осознаваемых мной реальностей... Естественная установка именно поэтому и является установкой повседневного сознания, что связана с миром, общим для многих людей» (там же: 44).

Следует заметить, что известная работа Бергера и Аукмана «Социальное конструирование реальности. Трактат по социологии знания» была опубликована в 60-е годы прошлого века, когда технологические новшества начинали оказывать все большее влияние на повседневную жизнь людей, однако ученые отдельно не акцентировали роль новых технологий в субъективном освоении социального мира. Спустя несколько десятилетий Н. Коулдри и А. Хепп (Couldry, Нерp, 2017) расширят и пересмотрят теоретические построения Бергера и Аукмана, подчеркивая значимость социальных медиа в конструировании современной реальности.

\section{ОСМЫСАЕНИЕ РОАИ ИНФОРМАЦИОННЫХ ТЕХНОАОГИЙ}

\section{В КОНСТРУИРОВАНИИ НОВОЙ СОЦИААЬНОЙ РЕААЬНОСТИ}

В своих тезисах Коулдри и Хепп опираются на определяющую роль актов коммуникации в конструировании социального мира. Отличительной особенностью концептуальных построений ученых становится их ориентация на медиатизацию (там же: 16). Стоит уточнить, что в зарубежной исследовательской практике медиатизация рассматривается как концепт, раскрывающий двухсторонний характер развития общества и медиатехнологий, в результате взаимовлияния которых трансформируются процессы коммуникации. С одной стороны, медиа видоизменяют и специфицируют коммуникативные практики, с другой - материализуют и институционализируют их (Hepp, Breiter, Hasebrink, 2018: 4). Иными словами, медиа в процессах коммуникации выступают не просто опосредующим звеном, а могут изменять акты социальной интеракции.

Коулдри и Хепп указывают на то, что медийная сторона общественной жизни содержит материальную составляющую (медиа - объекты, связи, инфраструктуры, платформы), включенную в акты коммуникации. Именно в соединении материальных 
и социальных аспектов проявляется двойственный характер образования смыслов и формирования окружающей реальности (Couldry, Hepp 2017: 3).

В своих рассуждениях ученые опираются на положения материалистической феноменологии (materialist phenomenology), утверждая, что в феноменологическом подходе необходимо учитывать не только смысловую интерпретацию, но и материальную инфраструктуру социальных коммуникаций, что позволит понять, как конструируется реальность в эпоху медиатизации (там же: 6-7).

Преобразование социальных интеракций в медиатизированной реальности Коулдри и Хепп анализируют через фигурации. Аанный подход основывается на теоретических положениях Н. Элиаса, в определении которого фигурации представляют модели сплетения, формы взаимозависимых взаимодействий, объединяющих в едином контенте индивида и общество (Элиас, 2000). Как объясняет Хепп в одной из своих работ, коммуникативные фигурации (communicative figuration) представляют собой определенные модели коммуникационных взаимозависимостей, осуществляемых посредством медиа в определенных рамках (фрейм в понимании Гофмана), которые ориентируют акты коммуникации и придают смысл практикам фигурации (Нерр, 2014: 85).

Коулдри и Хепп полагают, что именно «...в деталях конкретных фигураций, в более сложных фигурациях, в общей сети “фигурационного порядка”, который составляют такие фигурации, - лучше всего прослеживаются последствия технологических процессов медиации возможных для нас социальных миров» (Couldry, Hepp, 2017: 11). Иными словами, медиатехнологии, включаясь в фигурации, артикулируют не только их особые свойства, но и связь между различными фигурациями.

По мнению Коулдри и Хепп, медиа изменили измерение социального времени и преобразовали организацию социального пространства, что влияет на повседневные взаимодействия. Так, использование цифровых медиаобъектов приводит к тому, что они задают свой ритм фигурациям, в том числе самому человеку, обладающим «индивидуальным» временем (там же: 105-110). Вместе с тем авторы утверждают, что распространение сети Интернет привело к развитию транслокальных коммуникаций, которые усложняют пространство социальных отношений и создают новые виды цифрового неравенства. Например, фигурации современных семей, которые во многом опосредованы использованием в коммуникациях медиатехнологий, дифференцируются в зависимости от того, какие цифровые устройства и в каком количестве доступны каждому члену семьи (там же: 87). При этом Коулдри и Хепп обращают внимание на несовпадение «метапространств» социальных акторов, которые отражают разные возможности индивида взаимодействовать с социальным пространством и общаться с другими людьми в зависимости от доступных медиатехнологий (там же: 89).

По мнению западных авторов, современное общество сталкивается с новой волной медиатизации, что связано с изменением качественных характеристик медиасреды. Особенностью развития современных медиа является их цифровизация, которая, в свою очередь, связана с датификацией. Ученые считают, что посредством специальных алгоритмов цифровые медиа производят данные, которые могут использоваться в разных целях. В частности, онлайн-коммуникации на основе цифровых платформ создают базу больших данных, а онлайн-поиски или покупки оставляют «цифровые дорожки» (digital traces). Тем самым процесс социального конструирования реальности теперь включает не только коммуникации между людьми, но и автоматизацию, 
калькуляцию данных, производимых при использовании цифровых устройств. Из этого следует, что «социальный мир все больше и больше конструируется через датификацию» (Hepp, Breiter, Hasebrink 2018: 6).

Таким образом, различные аспекты конструирования социальной реальности были переопределены в контексте развития техносоциального мира. Примечательно и то, что феноменологические размышления о взаимодействии познающего субъекта и компьютерных систем получили концептуальное выражение в молодой междисциплинарной отрасли - человеко-компьютерное взаимодействие (human-computer interaction, HCI). Центральное место в плоскости рассуждений об особенностях взаимодействия индивида с компьютером в контексте феноменологии отводится формируемому смыслу и смыслообразованию. Исходя из феноменологической установки, утверждается, что знания пользователя, как и формируемые смыслы, ситуационно опосредованы, понимание людьми мира, самих себя, в том числе в рамках человекокомпьютерного взаимодействия, зависит от условий физического и социального окружения (Harrison, Tatar, Sengers, 2007: 7-8). Поэтому взаимодействие индивида и компьютерной техники необходимо анализировать с учетом ситуации, в которой оно осуществляется, так как сами по себе используемые в повседневной жизни знания не объясняют деятельность индивида (там же: 12). Сформулированные идеи предлагается развивать в области исследования человеко-компьютерного взаимодействия, где технические аспекты тесно переплетаются с человеческим фактором.

\section{ЗАКАЮЧЕНИЕ}

В современном мире повсеместное использование электронно-цифровых устройств трансформирует процессы коммуникации, изменяет источники получения знаний и их распределение, переносит формирование смыслов в техносоциальное пространство, где человек передает технологиям часть когнитивных функций. Становится очевидным, что информационные технологии не просто опосредуют освоение окружающей действительности, выступая в качестве нейтрального проводника, а преобразуют конструирование реальности.

В общем направлении научной мысли, в частности феноменологической с ее акцентацией ментальных основ построения реальности, можно отметить новое понимание значения технологий. Между тем стремительный рост инноваций может потребовать постановки новых исследовательских вопросов и их своевременного научного осмысления.

\section{СПИСОК АИТЕРАТУРЫ}

Бергер, П., Аукман, Т. (1995) Социальное конструирование реальности. Трактат по социологии знания. М. : Медиум. 323 с.

Верлен, Б. (2003) Субъективная точка зрения // Социологическое обозрение. Т. 3. № 4. C. $26-41$.

Гиглавый, А. В., Соколов, А. В., Абдрахманова, Г. И., Чулок, А. А., Буров, В. В. (2013) Аолгосрочные тренды развития сектора информационно-коммуникационных технологий // Форсайт. Т. 7. № 3. С. 6-24.

Гуссерль, Э. (2001) Собрание сочинений. М. : Гнозис ; Аом интеллектуальной книги. Т. 3 (1). Аогические исследования. 584 с.

Гуссерль, Э. (2010) Картезианские медитации. М. : Академический проект. 229 с.

Калинин, А. А. (2010) Иллюстрированные тезисы к прогнозу долгосрочного научно-технологического развития сектора информационно-коммуникационных технологий (ИКТ) России. 
M. : PTPC. 40 с. [Электронный ресурс] // Высшая школа экономики. URL: https://www.hse.ru/ data/2011/03/30/1211856048/Tezisi_AA_Kalin.pdf (дата обращения: 15.01.2019).

Карепова, С. Г., Пинчук, А. Н., Некрасов, С. В. (2018) Национальная безопасность: тенденции, перспективы, научно-практическая основа для укрепления - система показателей и индикаторов // Гуманитарные, социально-экономические и общественные науки. № 9. С. 35-43.

Китчин, Р. (2017) Большие данные, новые эпистемологии и смена парадигм // Социология: методология, методы, математическое моделирование (4М). № 44. С. 111-152.

Коркюф, Ф. (2002) Новые социологии. СПб. : Алетейя. 172 с.

Аукман, Т. (2007) Аспекты теории социальной коммуникации // Социологическое обозрение. Т. 6. № 3. С. 3-20.

Пинчук, А. Н. (2016) Образовательные практики в концептуальном поле социологии // Знание. Понимание. Умение. № 4. С. 321-331. DOI: 10.17805/zpu.2016.4.29

Пинчук, А. Н. (2017) Проблема образовательных практик обучающихся вузов как потребителей образовательных услуг // Вестник Адыгейского государственного университета. Серия 1: Регионоведение: философия, история, социология, юриспруденция, политология, культурология. № 3 (204). С. 143-151.

Ришир, М. (2014) 'Етохи', мерцание и редукция в феноменологии // (Пост)феноменология: новая феноменология во Франции и за ее пределами / сост. С. А. Шолохова, А. В. Ямпольская. М. : Академический проект. 288 с.

Саритас, О. (2013) Технологии совершенствования человека: перспективы и вызовы // Форсайт. Т. 7. № 1. С. 6-13.

Щюц, А. (2003а) О множественности реальностей // Социологическое обозрение. Т. 3. № 2. C. $3-34$.

Щюц, А. (2003b) Смысловая структура повседневного мира: очерки по феноменологической социологии. М. : Институт Фонда «Общественное мнение». 336 с.

Элиас, Н. (2000) Понятие фигурации // Журнал социологии и социальной антропологии. T. III. № 3. C. 62-65.

Эпштейн, М. (2004) Знак пробела: О Будущем гуманитарных наук. М. : Новое литературное обозрение. 864 с.

Couldry, N., Hepp, A. (2017) The Mediated Construction of Reality. Cambridge : Polity Press. $290 \mathrm{p}$.

Harrison, S., Tatar, D., Sengers, P. (2007) The Three Paradigms of HCI // Proceedings of the SIGCHI Conference on Human Factors in Computing Systems / ed. by Bo Begole, S. Payne, E. Churchill at al. New York : ACM Press. 1624 p.

Hepp, A. (2014) Communicative Figurations. Researching Cultures of Mediatization // Media Practice and Everyday Media Agency in Europe / ed. by L. Kramp, N. Carpentier, A. Hepp at al. Bremen : Edition Lumière. 375 p.

Hepp, A., Breiter, A., Hasebrink, U. (2018) Rethinking Transforming Communications: An Introduction // Communicative Figurations: Transforming Communications in Times of Deep Mediatization / ed. by A. Hepp, A. Breiter, U. Hasebrink. Cham : Palgrave Macmillan. 444 p.

Keisner, A., Raffo, J., Wunsch-Vincent, S. (2016) Robotics: Breakthrough Technologies, Innovation, Intellectual Property // Foresight and STI Governance. Vol. 10, no. 2. P. 7-27.

Kergroach, S. (2017) Industry 4.0: New Challenges and Opportunities for the Labour Market // Foresight and STI Governance. Vol. 11, no. 4. P. 6-8.

Аата поступления: 15.01.2019 2.

\section{CONSTRUCTION OF SOCIAL REALITY IN TECHNOSOCIAL SPACE: NEW ISSUES AND IDEAS A. N. PINCHUK \\ RAS INSTitute of SOCIAL AND Political ResearCH}

The article deals with the development of conceptual ideas about the construction of a new social reality in the context of the transition from social to technosocial space. The article presents global 
innovative trends that can, in the long run, significantly change the shape of information technology infrastructure, which is associated with serious social effects. The article analyzes the key works of the followers of the phenomenological approach, emphasizing the mental side of the construction of social reality. The author studied concepts of materialistic phenomenology, in which the role of media technologies in the formation of social reality is redefined.

Based on the concept of mediatization, the article shows the transformation of communicative figures, the transformation of social space and time, emphasizing the increasing role of datafication. The author points out the integration of phenomenological thought in the development of a new interdisciplinary branch of scientific knowledge - human-computer interaction.

Keywords: social reality; construction of social reality; innovative technologies; technosocial space; phenomenological approach; materialist phenomenology

\section{REFERENCES}

Berger, P. and Lukman, T. (1995) Sotsial' noe konstruirovanie real'nosti. Traktat po sotsiologii znaniia. Moscow, Medium. 323 p. (In Russ.).

Verlen, B. (2003) Sub'ektivnaia tochka zreniia // Sotsiologicheskoe obozrenie. T. 3. № 4. S. 26-41. (In Russ.).

Giglavyi, A. V., Sokolov, A. V., Abdrakhmanova, G. I., Chulok, A. A. and Burov, V. V. (2013) Dolgosrochnye trendy razvitiia sektora informatsionno-kommunikatsionnykh tekhnologii. Forsait, vol. 7, no. 3, pp. 6-24. (In Russ.).

Gusserl', E. (2001) Sobranie socbinenii. Moscow, Gnozis; Dom intellektual'noi knigi. Vol. 3 (1). Logicheskie issledovaniia. 584 p. (In Russ.).

Gusserl', E. (2010) Kartezianskie meditatsii. Moscow, Akademicheskii proekt. 229 p. (In Russ.).

Kalinin, A. A. (2010) Illiustrirovannye tezisy k prognozu dolgosrochnogo nauchno-tekhnologicheskogo razvitiia sektora informatsionno-kommunikatsionnykh tekhnologii (IKT) Rossii. M. : RTRS. 40 s. Vysshaia sbkola ekonomiki [online] Available at: https://www.hse.ru/data/2011/03/30/ 1211856048/Tezisi_AA_Kalin.pdf (access date: 15.01.2019). (In Russ.).

Karepova, S. G., Pinchuk, A. N. and Nekrasov, S. V. (2018) Natsional'naia bezopasnost': tendentsii, perspektivy, nauchno-prakticheskaia osnova dlia ukrepleniia - sistema pokazatelei i indikatorov. Gumanitarnye, sotsial'no-ekonomicheskie i obshchestvennye nauki, no. 9, pp. 35-43. (In Russ.).

Kitchin, R. (2017) Bol'shie dannye, novye epistemologii i smena paradigm. Sotsiologiia: metodologiia, metody, matematicheskoe modelirovanie (4M), no. 44, pp. 111-152. (In Russ.).

Korkiuf, F. (2002) Novye sotsiologii. St. Petersburg, Aleteiia. 172 p. (In Russ.).

Lukman, T. (2007) Aspekty teorii sotsial'noi kommunikatsii. Sotsiologicheskoe obozrenie, vol. 6, no. 3, pp. 3-20. (In Russ.).

Pinchuk, A. N. (2016) Obrazovatel'nye praktiki v kontseptual'nom pole sotsiologii. Znanie. Ponimanie. Umenie, no. 4, pp. 321-331. DOI: 10.17805/zpu.2016.4.29 (In Russ.).

Pinchuk, A. N. (2017) Problema obrazovatel'nykh praktik obuchaiushchikhsia vuzov kak potrebitelei obrazovatel'nykh uslug. Vestnik Adygeiskogo gosudarstvennogo universiteta. Seriia 1: Regionovedenie: filosofiia, istoriia, sotsiologiia, iurisprudentsiia, politologiia, kul'turologiia, no. 3 (204), pp. 143-151. (In Russ.).

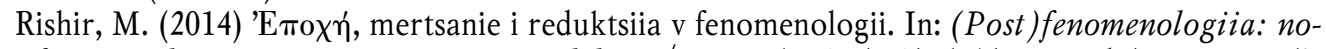
vaia fenomenologiia vo Frantsii $i$ za ee predelami / comp. by S. A. Sholokhova and A. V. Iampol'skaia. Moscow, Akademicheskii proekt. 288 p. (In Russ.).

Saritas, O. (2013) Tekhnologii sovershenstvovaniia cheloveka: perspektivy i vyzovy. Forsait, vol. 7, no. 1, pp. 6-13. (In Russ.).

Shchiuts, A. (2003a) O mnozhestvennosti real'nostei. Sotsiologicheskoe obozrenie, vol. 3, no. 2, pp. 3-34. (In Russ.).

Shchiuts, A. (2003b) Smyslovaia struktura povsednevnogo mira: ocherki po fenomenologicheskoi sotsiologii. Moscow, Institut Fonda «Obshchestvennoe mnenie». 336 p. (In Russ.).

Elias, N. (2000) Poniatie figuratsii. Zhurnal sotsiologii i sotsial' noi antropologii, vol. III, no. 3, pp. 62-65. (In Russ.). 
Epshtein, M. (2004) Znak probela: O Budushchem gumanitarnykb nauk. Moscow, Novoe literaturnoe obozrenie. 864 p. (In Russ.).

Couldry, N. and Hepp, A. (2017) The Mediated Construction of Reality. Cambridge, Polity Press. $290 \mathrm{p}$.

Harrison, S., Tatar, D. and Sengers, P. (2007) The Three Paradigms of HCI. In: Proceedings of the SIGCHI Conference on Human Factors in Computing Systems / ed. by Bo Begole, S. Payne, E. Churchill at al. New York, ACM Press. 1624 p.

Hepp, A. (2014) Communicative Figurations. Researching Cultures of Mediatization. In: Media Practice and Everyday Media Agency in Europe / ed. by L. Kramp, N. Carpentier, A. Hepp at al. Bremen, Edition Lumière. 375 p.

Hepp, A., Breiter, A. and Hasebrink, U. (2018) Rethinking Transforming Communications: An Introduction. In: Communicative Figurations: Transforming Communications in Times of Deep Mediatization / ed. by A. Hepp, A. Breiter, U. Hasebrink. Cham, Palgrave Macmillan. 444 p.

Keisner, A., Raffo, J. and Wunsch-Vincent, S. (2016) Robotics: Breakthrough Technologies, Innovation, Intellectual Property. Foresight and STI Governance, vol. 10, no. 2, pp. 7-27.

Kergroach, S. (2017) Industry 4.0: New Challenges and Opportunities for the Labour Market. Foresight and STI Governance, vol. 11, no. 4, pp. 6-8.

Submission date: 15.01.2019.

Пинчук Антонина Николаевна - кандидат социологических наук, научный сотрудник Института социально-политических исследований Российской академии наук. Адрес: 119333, Россия, г. Москва, ул. Фотиевой, д. 6, к. 1. Тел.: +7 (499) 530-28-84. E-mail: antonina.pinchuk27@bk.ru

Pinchuk Antonina Nikolayevna, Candidate of Social Science, Research Fellow, Institute of Social and Political Research; Russian Academy of Sciences. Postal address: 6, Bldg. 1, Fotievoi St., Moscow, Russian Federation, 119333. Tel.: +7 (499) 530-28-84. E-mail: antonina.pinchuk27@bk.ru 